\title{
Ultrafast Materials Probing with the LLNL Thomson X- Ray Source
}

P. Springer, S. Anderson, W. Brown, C. Barty, R. Cauble, J. Crane, H. Cynn, C. Ebbers, D. Fittinghoff, D. Gibson, F. Hartemann, I, Jovanovich, J. Kuba, G. LeSage, A. McMahan, R. Minich, J. Moriarty, B. Remington, D. Slaughter, F.H. Steitz, A. Tremaine, C.-S. Yoo, J. Rosenzweig, T. Ditmire

This article was submitted to The $21^{\text {st }}$ International LINAC Conference, Gyeonju, Korea, August 19-23, 2002

U.S. Department of Energy

Lawrence

Livermore

National

Laboratory

September 3, 2002 


\section{DISCLAIMER}

This document was prepared as an account of work sponsored by an agency of the United States Government. Neither the United States Government nor the University of California nor any of their employees, makes any warranty, express or implied, or assumes any legal liability or responsibility for the accuracy, completeness, or usefulness of any information, apparatus, product, or process disclosed, or represents that its use would not infringe privately owned rights. Reference herein to any specific commercial product, process, or service by trade name, trademark, manufacturer, or otherwise, does not necessarily constitute or imply its endorsement, recommendation, or favoring by the United States Government or the University of California. The views and opinions of authors expressed herein do not necessarily state or reflect those of the United States Government or the University of California, and shall not be used for advertising or product endorsement purposes.

This is a preprint of a paper intended for publication in a journal or proceedings. Since changes may be made before publication, this preprint is made available with the understanding that it will not be cited or reproduced without the permission of the author.

This report has been reproduced directly from the best available copy.

Available electronically at http://www.doc.gov/bridge

Available for a processing fee to U.S. Department of Energy

And its contractors in paper from

U.S. Department of Energy

Office of Scientific and Technical Information

P.O. Box 62

Oak Ridge, TN 37831-0062

Telephone: (865) 576-8401

Facsimile: (865) 576-5728

E-mail: reports@adonis.osti.gov

Available for the sale to the public from

U.S. Department of Commerce

National Technical Information Service

5285 Port Royal Road

Springfield, VA 22161

Telephone: (800) 553-6847

Facsimile: (703) 605-6900

E-mail: orders@ntis.fedworld.gov

Online ordering: http://www.ntis.gov/ordering.htm

\section{OR}

Lawrence Livermore National Laboratory

Technical Information Department's Digital Library

http://www.llnl.gov/tid/Library.html 


\section{ULTRAFAST MATERIALS PROBING WITH THE LLNL THOMSON X-RAY SOURCE}

P. Springer, S. Anderson, W. Brown, C. Barty, R. Cauble, J Crane, H. Cynn, C. Ebbers, D. Fittinghoff, D. Gibson, F. Hartemann, I. Jovanovich, J. Kuba, G. LeSage, A. McMahan, R. Minich, J. Moriarty, B. Remington, D. Slaughter,

F. H. Steitz, A. Tremaine, C-s. Yoo, LLNL, Livermore, CA., 94550, USA

J. Rosenzweig, UCLA, LA., CA., 90095, USA

T. Ditmire, Univerisy of Texas, Austin, TX, 85721, USA

\begin{abstract}
The use of short laser pulses to generate very high brightness, ultra short (fs to ps) $\mathrm{x}$-ray pulses is a topic of great interest. In principle, femtosecond-scale pump-probe experiments can be used to temporally resolve structural dynamics of materials on the time scale of atomic motion. The development of sub-ps $\mathrm{x}$-ray pulses will make possible a wide range of materials and plasma physics studies with unprecedented time resolution. The Thomson scattering project at LLNL will provide such a novel $\mathrm{x}$-ray source of high power using short laser pulses and a high brightness, relativistic electron bunch. The system is based on a $5 \mathrm{~mm}$-mrad normalized emittance photoinjector, $100 \mathrm{MeV}$ electron RF linac, and a $300 \mathrm{~mJ}$, 35 fs solid-state laser system. The Thomson source will produce ultra fast pulses with $\mathrm{x}$-ray energies $(60 \mathrm{keV})$ capable of probing into high- $\mathrm{Z}$ metals.
\end{abstract}

\section{INTRODUCTION}

Initial fast dynamic studies of laser excited materials [1] have been pursued in recent years using time-resolved $x$ ray detectors at synchrotron sources and laser-plasma $x$-ray sources in pump-probe experiments [2,3]. Third generation synchrotrons have been critical for $\mathrm{x}$-ray studies in materials, but have a major limitation: although they probe structure on the atomic length scale, their time resolution $(\sim 100 \mathrm{ps})$ is not well-matched to the natural dynamics of elemental processes in solids, such as the time scale for atomic motion ( $10-50 \mathrm{fs})$. Laser melting in semiconductors may involve excitation, electronphonon coupling, melt front motion and shock waves, all with $<30$ ps relevant timescales. X-rays produced from hot plasma sources can achieve very short pulse lengths, but the low peak brightness forces multiple shot measurements and may lead to target destruction by the pump excitation.

We have undertaken the development of an $\mathrm{x}$-ray source based on laser scattering off a relativistic electron bunch. This Thomson scattering approach offers the potential to produce $\mathrm{x}$-rays in a unique regime. The LLNL source will exceed peak brilliance currently offered at third generation synchrotron light sources while delivering pulse lengths below $1 \mathrm{ps}$. A temporally compressed laser pulse is focused onto a short relativistic electron pulse. Fig. 1 shows how the resulting hard $\mathrm{x}$-rays can then be used for numerous laser-x-ray pump probe experiments, similar to extended $\mathrm{x}$-ray absorption fine structure (EXAFS) spectroscopy [1].

\section{EXPERIMENTAL DESIGN}

Ultra fast $\mathrm{x}$-ray pulses are generated by scattering a high power, ultra short $800 \mathrm{~nm}$ laser pulse off

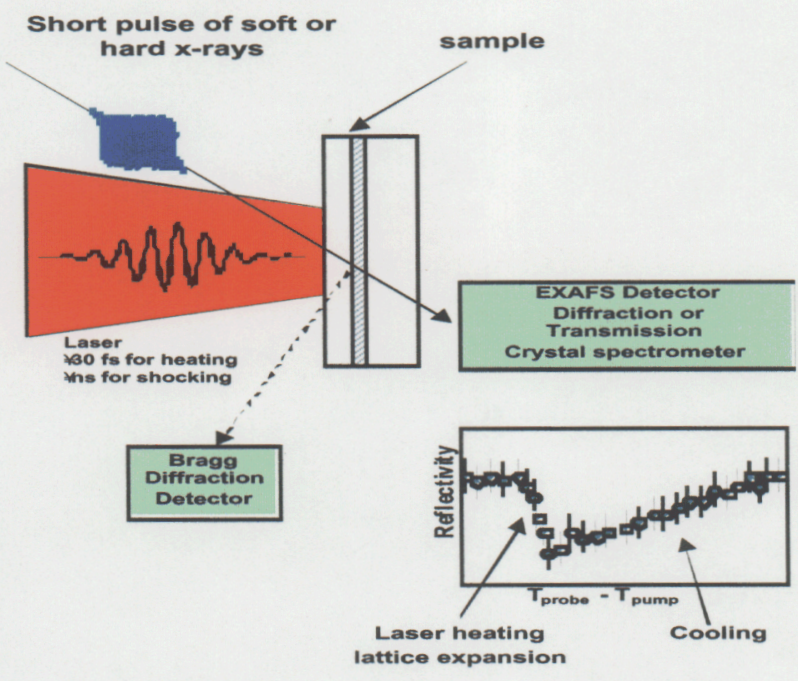

Fig. 1 Schematic of laser-x-ray pump-probe experiments

of relativistic electrons at the LLNL $100 \mathrm{MeV}$ electron Linac. The scattered laser photons are relativistically up shifted in frequency into the hard $\mathrm{x}$-ray range, and are emitted in a narrow cone about the electron beam direction.

As viewed in the frame of the moving electrons, the incident laser pulse train appears as an electromagnetic undulator of wavelength $\lambda_{\mathrm{u}}=\lambda_{\mathrm{L}} / \gamma(1-\cos \Psi)$, where $\gamma=\mathrm{E} / \mathrm{m}_{0} \mathrm{c}^{2}$ and $\Psi$ is the incident angle between electron and laser beams as shown in Figure 2. The electrons radiate photons, which are up shifted back into the laboratory frame by a second factor of $2 \gamma$. The $x$-ray wavelength is therefore related to the initial laser wavelength by

$$
\lambda_{\mathrm{x}}=\lambda_{\mathrm{L}} / 2 \gamma^{2}(1-\cos \Psi)
$$


where $\lambda_{\mathrm{L}}$ is the laser wavelength. In the laboratory frame, the up shifted $\mathrm{x}$-rays are confined to a narrow cone with opening angle $\sim 1 / \gamma$, and their energy varies with observation angle in the laboratory due to the kinematics of the Lorentz transformation. The laboratory $\mathrm{x}$-ray energy (for scattering of the fundamental) is:

$$
\mathrm{E}_{\mathrm{x}}=\mathrm{E}_{\mathrm{L}} 2 \gamma^{2}(1-\cos \Psi) /\left(1+\gamma^{2} \theta^{2}+\mathrm{a}_{\mathrm{o}}^{2}\right)
$$

where $E_{L}$ is the laser photon energy, $\theta$ is the observation angle and $\mathrm{a}_{0}$ is the usual normalized vector potential of the laser field, which is analogous to the $\mathrm{K}$ parameter of a static field undulator.

The LBNL Advanced Light Source injector Linac previously demonstrated generation of sub-ps pulses of hard $\mathrm{x}$-rays by Thomson scattering [4,5]. The LLNL Thomson source presently under development is expected to achieve an $\mathrm{x}$-ray beam flux some four to five orders of magnitude larger, enabling the accumulation of sufficient data for a high quality Bragg diffraction spectrum on each shot.

We expect to produce up to $10^{8} \mathrm{x}$-ray photons in a $\sim 100$ fs pulse, and up to $10^{10} \mathrm{x}$-rays in a 1-10 ps pulse, by scattering the laser respectively either across the electron beam $\left(\Psi=90^{\circ}\right)$ which minimizes the temporal overlap, or in a head-on $\left(\Psi=180^{\circ}\right)$ geometry $[6,7]$, which maximizes the interaction of the electrons and Falcon laser. To achieve enhancements over other Thomson sources, we are making two straightforward but critical improvements: a low emittance electron beam derived from a photoinjector and a high power, $10 \mathrm{TW}$ Ti:sapphire laser with an future upgrade to $100 \mathrm{TW}$.

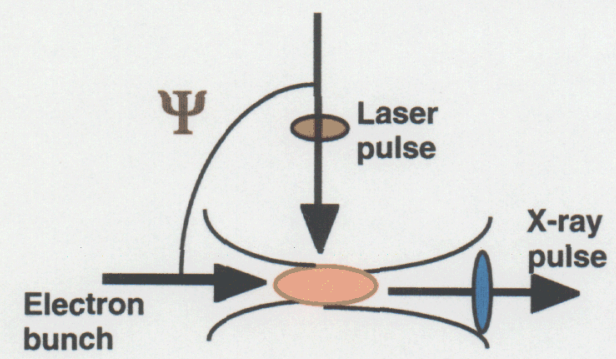

Fig. 2 Thomson scattering geometry

\section{ELECTRON INJECTOR AND LASER}

The Falcon laser is a Ti:sapphire laser based on chirped pulse amplification. To date, we have integrated the Falcon laser with the Linac and made preparations to transport the laser pulses to the electron beam.

The LLNL Falcon laser [8,9] currently produces $300 \mathrm{~mJ}$ pulses at a $10 \mathrm{~Hz}$ repitition rate. Each pulse width can be as short as $35 \mathrm{fs}$ giving nearly three decades higher brightness than in previous scattering experiments.
Anticipated laser upgrades to $4 \mathrm{~J}$ coupled with increases in electron bunch charge will extend this advantage to 4-5 decades.

An RF photocathode electron injector [10] produces the high brightness, low emittance electron beams. This photoinjector, shown schematically in Figure 3 below, has been designed, constructed, and characterized.

A pulse of S-band (2.8545 GHz) RF input with $7 \mathrm{MW}$ peak power and $3 \mathrm{~ms}$ pulse length produces a peak standing wave electric field of $100 \mathrm{MV} / \mathrm{m}$ that accelerates the electrons to $5 \mathrm{MeV}$ in less than a $10 \mathrm{~cm}$ distance. A laser pulse, split from the Falcon laser oscillator is amplified and frequency tripled before striking a copper photocathode near the peak RF field. The electrons bunches produced have 1-10 nC of charge with pulse lengths of about 10ps. Focusing solenoids are employed to preserve the transverse emittance [11] of the electron beam immediately off the cathode and to help match the electron beam into 4 slac type linac sections, which increase the beam energy to $40-100 \mathrm{MeV}$.

Initial production of Thomson x-rays at LLNL utilized $20 \mathrm{~mJ}$ laser pulses and $5 \mathrm{MeV}$ electron bunches from the photoinjector at $10 \mathrm{~Hz}$. Successful overlap of the two beam demonstrated $0.6 \mathrm{keV}$ x-ray production [12]. This result established the ability to focus the laser and electron beams to small spots and to synchronize both beams. For high flux x-rays, the electron beam, with an energy of $100 \mathrm{MeV}$, and falcon laser will both need to be focused to under 40 microns with synchronization $<3$ ps

At high energy $(100 \mathrm{MeV})$ the minimum focal spot obtainable for the electron beam is emittance dominated for bunch charges in the $\mathrm{nC}$ range. Simulations

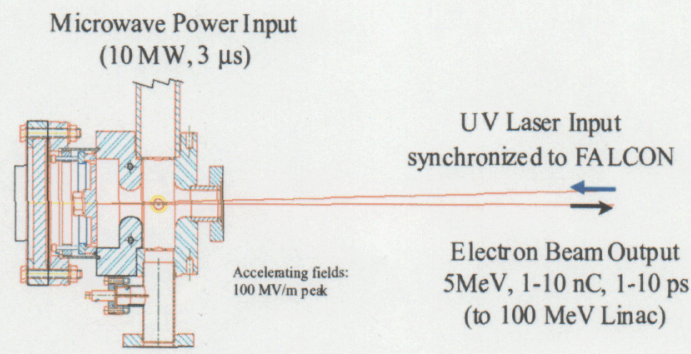

Vacuum Pumping Port

Fig. 4 Photo-injector gun

of the electron beam emittance have been carried out using the PARMELLA code and results have been used to predict beam performance for the Thomson scattering experiments. The results predict a low emittance beam that can be focused to a $20 \mu \mathrm{m}$ spot with a convergence angle of $5 \mathrm{mrad}$. To accomplish this, the required normalized transverse emittance must be less 
than $10 \mathrm{~mm}$-mrad, thus the use of a photoinjector is advantageous.

A quadrupole triplet will provide the final focus of the electron beam before interaction with the Falcon laser. In a strong focusing field, low energy spread is also important to maintain a short longitudinal width at the focus, which the photoinjector can produce.

Ultimately, the goal is to place as many monoenergetic, collimated electrons as possible into the laser focus for the production of up-shifted x-ray photons. Achieving a very high peak current is most important for the transverse interaction of the Falcon laser pulse and electron beam. To attain the high current, the electron energy in the bunch will be chirped by a dephased Linac section, allowing for a ballistic compression of the electron beam from 10ps to 2ps [13]. A complementary dephased Linac section removes the energy chirp after compression for maximum beam peak current. More compression in the electron beam would cause a detrimental increase in the emittance, and the energy spread would be too large to be completely removed by the complementary Linac section.

\section{PHOTO ELECTRON BEAM MEASUREMENTS}

Once the initial Thomson scattering experiments were completed, the photo-injector was installed in the Linac beamline where acceleration up to $100 \mathrm{MeV}$ was possible. The photo-cathode uv drive laser transport was completed, and intial commissioning of the photo beamline started with a $130 \mu \mathrm{J}, 2 \mathrm{~mm}$ spot on the cathode with upgrades to $1 \mathrm{~mJ}$ and smaller spots planned for the future.

Intial emittance measurements using a quad scan technique were taken and the data shown in Fig. 5. For a $300 \mathrm{pC}, 60 \mathrm{MeV}$ bunch, a normalized emittance of $15 \mathrm{~mm}$-mrad was obtained. Simulations show that an emittance of this amount will

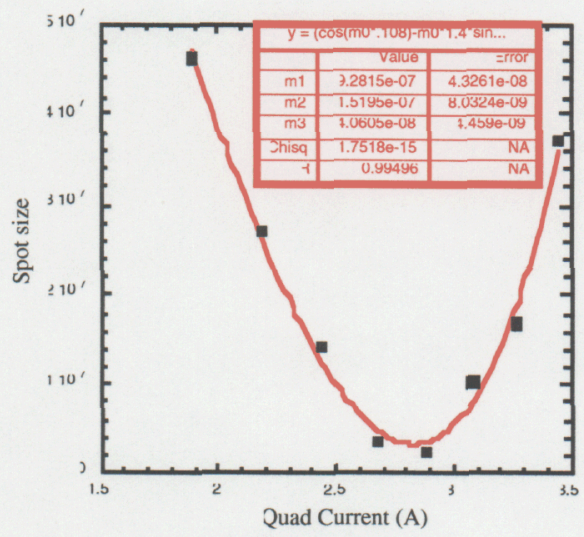

Fig. 5 Emittance measurements at $60 \mathrm{MeV}$ using a Quad Scan technique

degrade the number of Thomson photons, but a significant flux of $x$-rays can still be expected. In fact, the simulations show that our beamline magnets could focus the present electron beam to a transverse size of $40 \mu \mathrm{m}$, and upon interacting with the Falcon laser, generate $5 * 10^{6}$ $\mathrm{x}$-ray photons. However, several straight forward upgrades can be made, and the emittance should reduce to the desired range, $<10 \mathrm{~mm}$-mrad. The laser spot was not Gausssian and neither the laser shape or size in the longitudinal and transverse dimensions were optimized for minimum emittance, but had hot areas on the cathode and best Parmela results are for a spot of $1 \mathrm{~mm}$ not the $2 \mathrm{~mm}$ used for the measurements. Furthermore, lack of optimization of the solenoid field and gun phase because of time constraints caused the measured emittance above to be an upper bound,

\section{SUMMARY}

A high power (10 TW) short pulse ( $35 \mathrm{fs}$ ) laser has been integrated with a $100 \mathrm{MeV}$ electron Linac to provide a Thomson scattering source of $\mathrm{x}$-rays tunable in wavelength over a range of $10-200 \mathrm{keV}$. By driving the photoinjectro/Linac with the same short pulse as the laser, good synchronization of 1-2 ps between the two is possible. Very low emittance electron bunches allow for tightly focused spots at the interaction. When properly focused the scattered beams are predicted to provide an unprecedented high brightness (up to $10^{11} \mathrm{x}$-rays per pulse) in durations as short as 1-2 ps, and slightly lower intensity in durations as short as 100 fs. The $10 \%$ bandwidth, tunable wavelength range, and high per-pulse flux of the Thomson source will make it ideal for performing absorption edge spectroscopy of metals at a variety of wavelengths

This work was performed under the auspices of the U.S. Department of Energy by Lawrence Livermore National Laboratory under contract no. W-7405-Eng-48.

\section{REFERENCES}

[1] P. A. Lee, P. H. Citrin, P. Eisenberger, B. M. Kincaid, "Extended X-ray absorption fine structure- its strengths and limitations as a structural tool", Rev. Mod. Phys 53, 769-806 (1981).

[2] C. Rose-Petruck, et al., "Picosecond-milliangstrom lattice dynamics measured by ultrafast X-ray diffraction", Nature 398, 310-312 (1999).

[3]. C. W. Siders, et al., "Detection of nonthermal melting by ultrafast X-ray diffraction", Science $\underline{\mathbf{2 8 6}}$, 1340-1342 (1999).

[4] R. W. Schoenlein, et al., "Femtosecond X-ray pulses at $0.4 \mathrm{~A}$ generated by $90^{\circ}$ Thomson scattering: $\mathrm{A}$ tool for 
probing the structural dynamics of materials", Science 274, 236-238 (1996).

[5] W. P. Leemans, et al., "Interaction of relativistic electrons with ultrashort laser pulses: Generation of femtosecond x-rays and microprobing of electron beams", IEEE J. Quant. Elec. 33, 1925-1933 (1997).

[6]E. Esarey, S. K. Ride, P. Sprangle, "Nonlinear Thomson scattering of intense laser pulses from beams and plasmas", Phys. Rev. E 48, 3003-3021 (1993).

[7] F. V. Hartemann, et al., "Three-dimensional theory of emittance in Compton scattering and $\mathrm{X}$-ray protein crystallography", Phys. Rev. E 64, (2001).

[8] V. P. Yanovsky, et al., "Multip-terawatt laser-linac facility", Conference on Lasers and Electron Optics, 410, (1999), Washington, DC, OSA Technical Digest.

[9] T. Ditmire, M. D. Perry, "High intensity physics with a table-top 20 TW laser system ", Lawrence Livermore National Laboratory, UCRL-ID-133293, 1999.1

[10] G. Lesage, et al. RF Photoinjector Development for a Short-Pulse, Hard X-ray Thomson Scattering Source , Proceedings of the 2000 Particle Accelerator Conference, Chicago, IL., 2000.

[11] B.E Carlsten, New Photoelectric injector design for the Los Alamos National Laboratory xuv Accelerator, Nulc.Instrum Methods Phys. Res., Sect. A, 285, P. 313 (1989)

[12] J. Crane, Private Communication.

[13] L. Serafini, A. Bacci, and M. Ferrario, Ultra-short electron bunch generation with a rectilinear compressor. In Proceedings of the 2001 Particle Accelerator

Conference, p. 2242. 